Tropical Journal of Pharmaceutical Research September 2017; 16 (9): 2149-2154

ISSN: 1596-5996 (print); 1596-9827 (electronic)

(C) Pharmacotherapy Group, Faculty of Pharmacy, University of Benin, Benin City, 300001 Nigeria.

All rights reserved.

Available online at http://www.tjpr.org

Original Research Article

http://dx.doi.org/10.4314/tjpr.v16i9.15

\title{
Chloroquine prevents acute kidney injury induced by lipopolysaccharide in rats via inhibition of inflammatory factors
}

\author{
Shao-Yun Zhang ${ }^{1}$, Hong-Qiang $\mathrm{Xia}^{1}$ and Si-Ling Cui ${ }^{2 \star}$ \\ ${ }^{1}$ Department of Critical Care Medicine, Laiwu Iron and Steel Group Co, Ltd hospital, Laiwu, Shandong, 271104, ${ }^{2}$ Department of \\ Real Rheumatology, Laiwu Iron and Steel Group Co, Ltd Hospital, Laiwu, Shandong , 271104, China
}

*For correspondence: Email: cuisilingcsl@gmail.com; Tel: 0086-634-6825700; Fax: 0086-634-6825700

Sent for review: 17 October 2016

Revised accepted: 11 August 2017

\begin{abstract}
Purpose: To investigate the role of chloroquine (CQ) in lipopolysaccharide (LPS)-induced renal injury in rats.

Methods: Rats were assigned to one of four groups $(n=10)$. Control group was only given saline solution, whereas the model control, $L P S+C Q$, and $L P S+$ yohimbine $(Y O H)+C Q$ groups were administered LPS intraperitoneally. At the end of the study, blood urea nitrogen (BUN) and creatinine (Cr) levels were determined.

Results: $C Q$ treatment significantly decreased the blood concentrations of tissue necrosis factor alpha (TNF- $\alpha$ ), interleukin-6 (IL-6), IL-18, BUN, and $\mathrm{Cr}$ in the model control rats. There were also significant decreases in the levels of high mobility group protein 1 and kidney injury molecule-1 in the renal injury rats compared to the model control group. However, the inhibitory effects of CQ in the LPS-treated rats were blocked by treatment with $\mathrm{YOH}$, an a-2-adrenergic receptor antagonist.

Conclusions: Treatment with $C Q$ attenuates LPS-induced renal injury by inhibiting inflammatory response.
\end{abstract}

Keywords: Creatinine, Chloroquine, Inflammatory reactions, Kidney injury, Lipopolysaccharide

\begin{abstract}
Tropical Journal of Pharmaceutical Research is indexed by Science Citation Index (SciSearch), Scopus, International Pharmaceutical Abstract, Chemical Abstracts, Embase, Index Copernicus, EBSCO, African Index Medicus, JournalSeek, Journal Citation Reports/Science Edition, Directory of Open Access Journals (DOAJ), African Journal Online, Bioline International, Open-J-Gate and Pharmacy Abstracts
\end{abstract}

\section{INTRODUCTION}

Various factors can trigger a systemic inflammatory response, which is characterized by a reduction in oxygen uptake and myocardial contractility such as pathogen administration, trauma, hypoxia, reperfusion injury, and postoperative sepsis [1]. Sepsis has a mortality rate of $40-80 \%$ and most commonly targets the kidneys [2]. Acute kidney injury (AKI) induced by sepsis has a $70 \%$ mortality rate $[3,4]$. Factors related to the onset of inflammation include tissue necrosis factor alpha (TNF- $\alpha$ ), interleukin6 (IL-6), and IL-18, which are expressed at higher concentrations under pathological conditions. Of these, IL-18 is a biomarker of AKI [5]. Injuries to organs are induced by the IL-18mediated expression of TNF- $\alpha$ and IL-6, which initiate an inflammatory reaction [6]. It is believed that inhibiting this inflammatory reaction is a promising strategy for preventing organ injury.

Chloroquine (CQ, Figure 1) and its analogs exhibit a wide spectrum of biological activities including anti-cancer [7] and anti-hepatitis $C$ virus $[8,9]$ effects. CQ also readily crosses the bloodbrain barrier [10]. In addition, CQ analogs such as hydroxychloroquine have shown promise for the treatment of systemic lupus erythematosus 
[11] and rheumatoid arthritis [12]. Experiments using a number of $\mathrm{CQ}$ analogs in a human diploid embryonic lung cell line (MRC-5) revealed their potential biological properties and lack of cytotoxic effects [13]. Therefore, this study evaluated the nephroprotective effects of $C Q$ in LPS-induced sepsis.

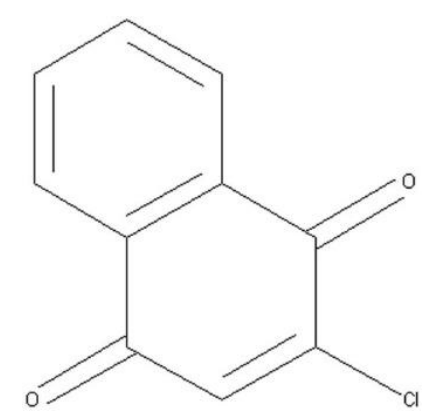

Figure 1: Chemical structure of chloroquine (CQ)

\section{EXPERIMENTAL}

\section{Animals}

Male 18-week-old Sprague-Dawley rats were obtained from Beijing Vital River Experimental Animal Technology (Beijing, China). The study was performed according to the European guidelines for animal use [14]. Study approval was obtained from the animal research ethics committee of The Provincial Hospital Affiliated with Shandong University (Shandong Sheng, China)

\section{Drugs}

$C Q$ was dissolved in dimethyl sulfoxide and stored at $-20^{\circ} \mathrm{C}$. Yohimbine $(\mathrm{YOH})$ was obtained from Sigma-Aldrich (St. Louis, MO, USA).

\section{Treatment protocols}

The rats were separated into four groups: untreated normal control group, model control group that was administered LPS intraperitoneally (i.p.), LPS + CQ treatment group that was treated with CQ after LPS administration, and LPS + YOH + CQ treatment group that was pretreated with $\mathrm{YOH}$ followed by CQ treatment after LPS administration. LPS, CQ, and $\mathrm{YOH}$ were administered at doses of 4,5 , and $1 \mathrm{mg} / \mathrm{kg}$ body weight, respectively after $12 \mathrm{~h}$.

\section{Kidney damage analysis}

The rats were sacrificed by pentobarbital overdose $(70 \mathrm{mg} / \mathrm{kg}$, i.p.) after $12 \mathrm{~h}$ and the blood Cr, BUN, IL-6, IL-18, and TNF- $\alpha$ levels were determined using blood collected from the abdominal artery. An automated biochemistry analyzer (Hitachi 7600-020/7170A; Hitachi HighTechnologies, Tokyo, Japan) was used to measure the $\mathrm{Cr}$ and BUN levels. Immediately after sacrifice, the left kidney was isolated from all of the rats under liquid nitrogen, fixed in formalin, and stored at $-78{ }^{\circ} \mathrm{C}$. In addition, two biomarker molecules, high mobility group protein 1 (HMGB-1) and kidney injury molecule-1 (KIM1 ), were measured in the renal tissue sections. To examine renal histology, renal tissues were fixed in formalin, embedded in paraffin, and examined under a microscope at $400 \times$ magnification after hematoxylin and eosin staining.

\section{Measuring TNF-A, IL-6, and IL-18 levels in the rat plasma}

To determine the TNF- $\alpha$, IL-18, and IL-6 levels in the rat plasma, blood samples were taken from the rats and centrifuged at $12000 \times g$ for $10 \mathrm{~min}$. Then the serum was isolated and stored at -78 ${ }^{\circ} \mathrm{C}$. IL-6, IL-18, and TNF- $\alpha$ concentrations were measured using ELISA kits (Nanjing KeyGen Biotech, Jiangsu, China).

\section{Western blot analysis}

The renal tissue samples were washed twice with phosphate-buffered saline (PBS) and subsequently lysed in lysis buffer containing Tris$\mathrm{HCl}$ pH $7.4(50 \mu \mathrm{M})$, sodium chloride $(137 \mu \mathrm{M})$, $10 \%$ glycerol, $100 \mu \mathrm{M} \mathrm{Na}{ }_{2}\left(\mathrm{VO}_{3}\right), 1 \mu \mathrm{M}$ PMSF, aprotinin $(10 \mathrm{mg} / \mathrm{mL})$, leupeptin $(10 \mathrm{mg} / \mathrm{mL}), 1 \%$ NP-40, and cocktail (5 $\mu \mathrm{M})$. The bicinchoninic acid assay was used to determine the protein concentration. The protein samples were loaded on $10 \%$ polyacrylamide gels, resolved by electrophoresis, and electro transferred to poly (vinylidene fluoride) membranes using the semidry method. The membranes were washed with Tris-buffered saline Tween (TBST) and blocked in $5 \%$ non-fat dry milk for $12 \mathrm{~h}$. Subsequently, the membranes were incubated overnight with primary antibodies against KIM-1 and HMGB-1 (both purchased from Santa Cruz Biotechnology, Dallas, TX, USA), washed again with TBST, and incubated with secondary antibodies for $2 \mathrm{~h}$. A chemiluminescent detection system was used to detect the protein bands, which were quantified using the Quantity One software package (BioRad, Hercules, CA, USA) using GAPDH (Thermo Fisher Scientific, Fremont, CA, USA) as an internal control.

\section{Statistical analysis}

All of the experiments were conducted three times and the results are reported as the mean \pm 
SD. The results were compared using the Student's $t$-test and $p<0.05$ was considered statistically significant. SPSS software version 16.0 was used for the data analysis.

\section{RESULTS}

\section{Effects of $C Q$ on BUN and creatinine levels in rats with LPS-induced AKI}

The BUN and creatinine $(\mathrm{Cr})$ levels were markedly higher in the LPS-treated group than in the controls (Figure 2), and CQ treatment caused significant decreases in serum BUN and $\mathrm{Cr}$ levels in the LPS-induced sepsis rat model. However, the decrease in $\mathrm{Cr}$ and BUN caused by $C Q$ was inhibited in rats pretreated with the $\alpha-2$ - adrenergic receptor antagonist $\mathrm{YOH}$, and $\mathrm{Cr}$ and BUN levels were similar to those of rats injected with LPS.

The renal histology micrographs of LPS-treated and untreated control groups showed luminal swelling and flattened glomerular and renal tubule cells in LPS-treated rats. LPS treatment also induced degeneration of the tubular epithelium, the appearance of small tubular structures, and an inflammatory cell infiltrate. However, CQ treatment inhibited these changes, and the findings were similar to those of the nonLPS control group. Pretreating rats with $\mathrm{YOH}$ followed by $C Q$ treatment prevented the effects of $C Q$ treatment (Figure 3).
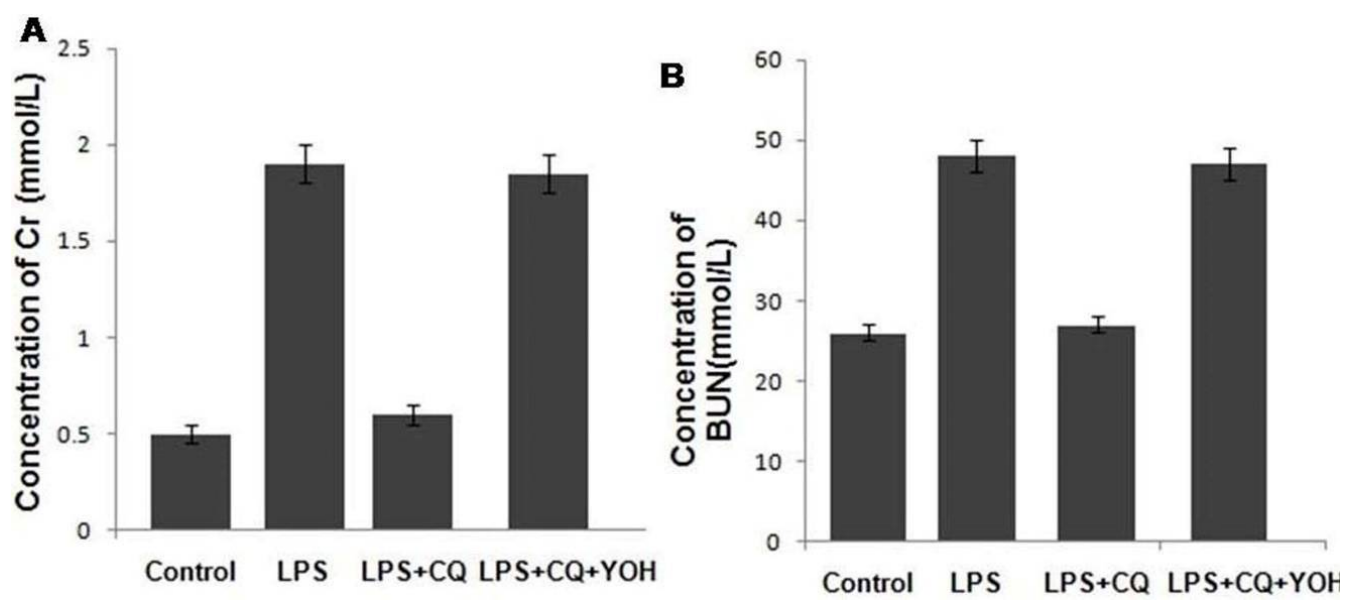

Figure 2: Effects of $\mathrm{CQ}$ and $\mathrm{YOH}$ on $\mathrm{Cr}$ and $\mathrm{BUN}$ levels in rats with LPS-induced renal injury. $\mathrm{CQ}$ treatment caused a significant decrease in serum levels of $\mathrm{Cr}$ and BUN in the LPS-induced kidney injury rat model
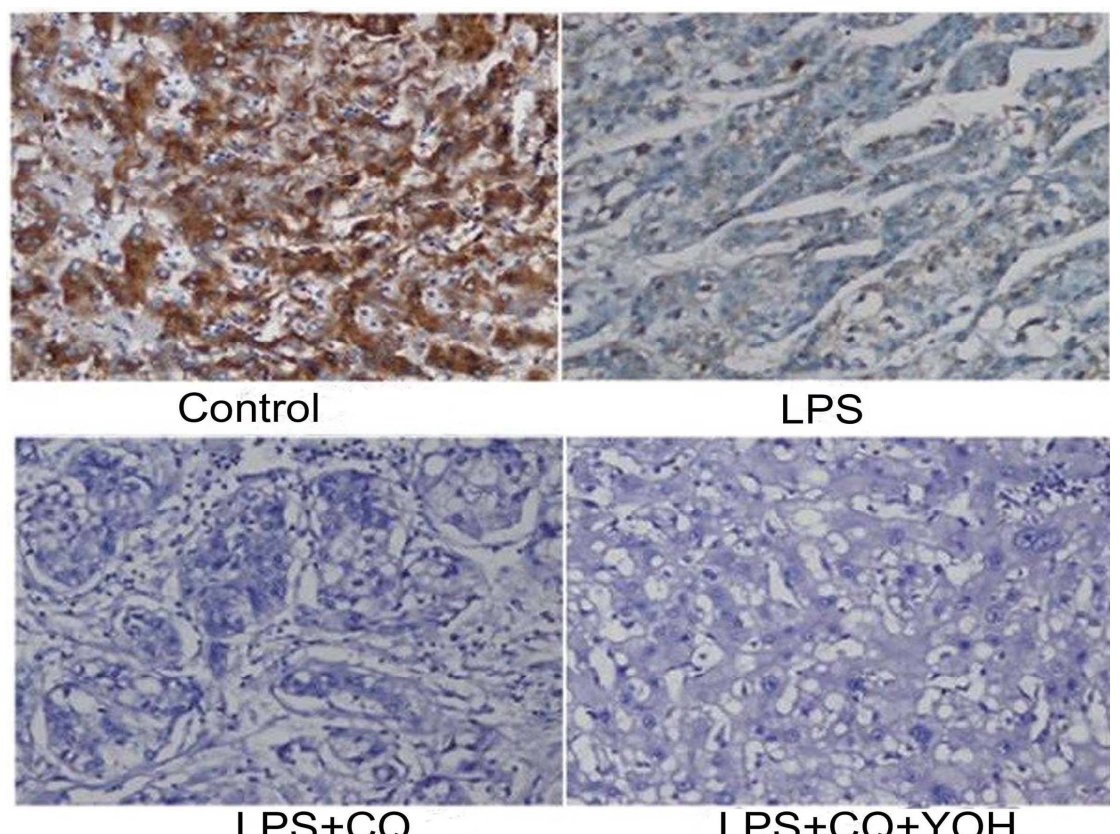

Figure 3: Effects of $\mathrm{CQ}$ and $\mathrm{YOH}$ on renal histology in LPS-induced renal injury in rats. The changes in kidney tissue histopathology were examined with hematoxylin and eosin staining. $\mathrm{CQ}$, chloroquine; $\mathrm{YOH}$, yohimbine; LPS, lipopolysaccharide; magnification $200 \times$ 
Effects of CQ on HMGB-1 and KIM-1 expression in the kidneys of LPS-treated rats

The analysis of KIM-1 and HMGB-1, biomarkers of kidney damage, revealed significantly greater expression in rats treated with LPS (Figure 4). However, CQ treatment resulted in marked decreases in KIM-1 and HMGB-1 expression in LPS-treated rats. Treatment of rats given LPS with $\mathrm{YOH}$ followed by $\mathrm{CQ}$ prevented the $\mathrm{CQ}$ mediated decreases in KIM-1 and HMGB-1.
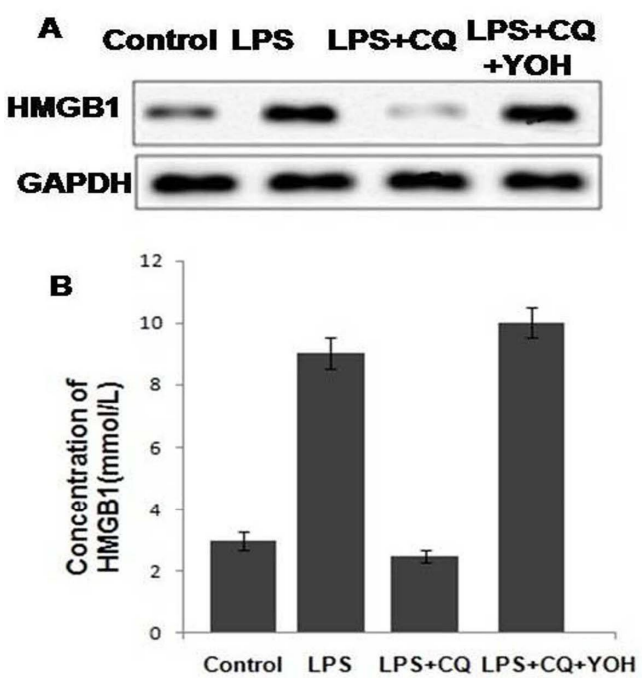

Effects of $C Q$ on the inflammatory reaction in the kidney

There was increased expression of the inflammatory factors IL-6, IL-18, and TNF- $\alpha$ in the LPS-treated rats (Figure 5). CQ treatment induced a marked decrease in the expression of all three inflammatory factors, whereas pretreatment with $\mathrm{YOH}$ inhibited the effects of $\mathrm{CQ}$.
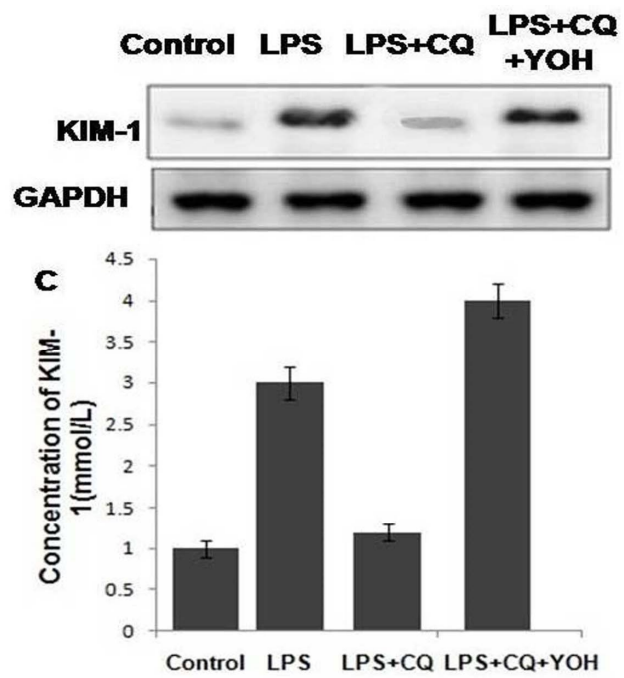

Figure 4: Effects of $\mathrm{CQ}$ and YOH on HMGB-1 and KIM-1 expression in the renal tissues. YOH, yohimbine; LPS, lipopolysaccharide
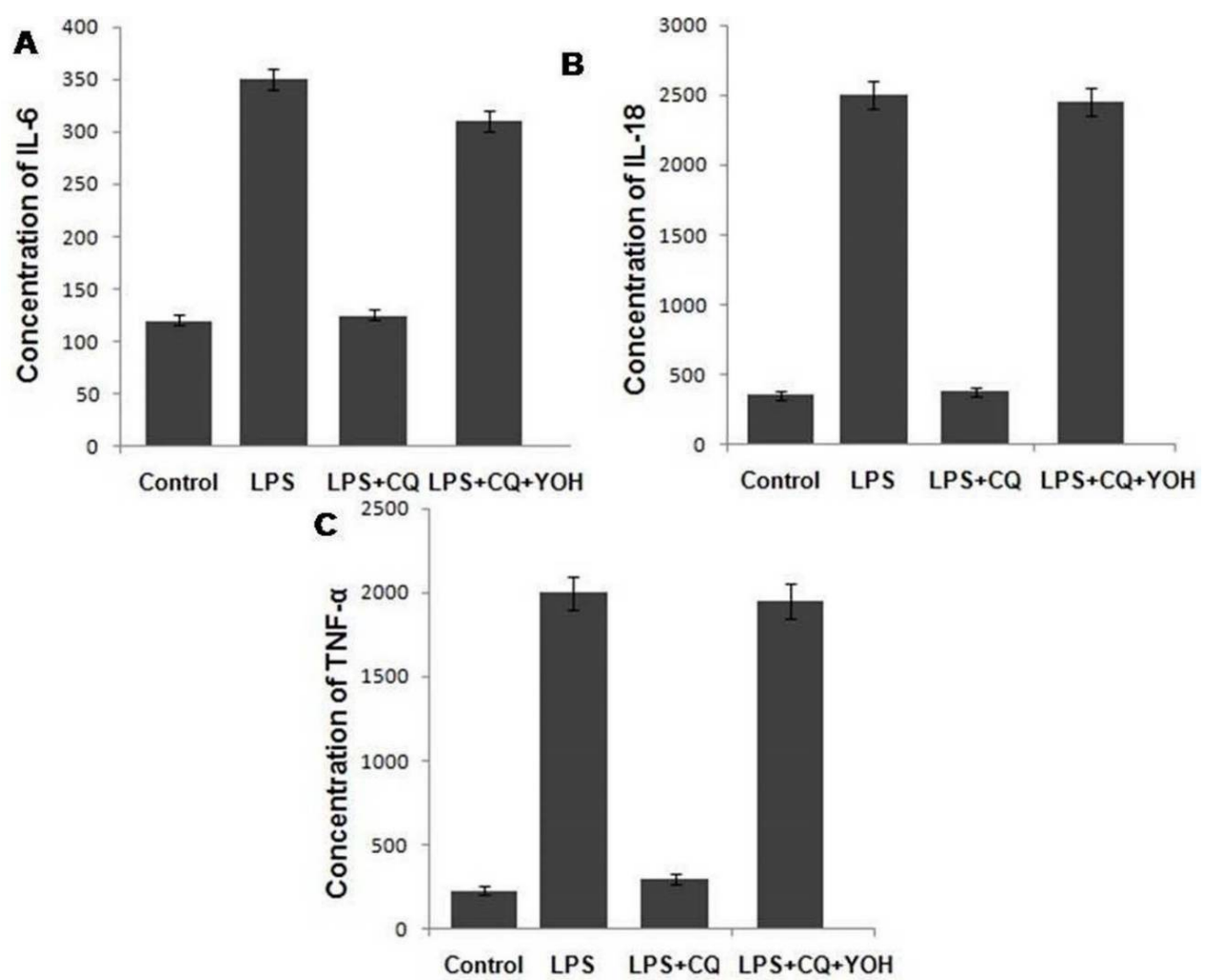

Figure 5: Effects of CQ and YOH on TNF- $\alpha$, IL-18, and IL-6 expression in rats with LPS-induced renal injury. IL, interleukin; TNF- $\alpha$, tumor necrosis factor- $\alpha$; YOH, yohimbine; LPS, lipopolysaccharide 


\section{DISCUSSION}

Renal tubule injury is the cause of renal failure in more than $80 \%$ of affected patients $[15,16]$. This study demonstrated the effects of CQ on AKI in rats administered LPS. CQ treatment inhibited the effects of LPS and prevented renal damage, as evidenced by the decrease in KIM-1 and HMGB-1 expression. Pre-treatment of LPStreated animals with $\mathrm{YOH}$ blocked the effects of $C Q$, suggesting that $C Q$ elicits its effects via the a-2 adrenoceptor. HMGB-1 binds to inflammatory mediators and induces the release of pro-inflammatory cytokines [17]. KIM-1, a transmembrane tubular protein, is expressed in the kidneys after renal injury and serves as a marker of renal injury [17]. Kidney injury involves an inflammatory reaction [18]. The reduction in the expression of factors responsible for inflammatory reactions caused by $C Q$, which was enhanced by LPS treatment, demonstrated the inhibitory effects of CQ on IL-6, IL-18, and TNF- $\alpha$ expression. The inflammatory reactions promoted by TNF- $\alpha$ and IL- 6 factors are induced by IL-18 and cause organ injury [19].

This study showed that CQ treatment in LPStreated rats inhibited kidney injury via the suppression of factors involved in inflammation such as IL-6, IL-18, and TNF- $\alpha$. However, pretreatment with the $\alpha$-2-adrenergic receptor antagonist $\mathrm{YOH}$ blocked the effects of $\mathrm{CQ}$ in the renal tubules, collecting ducts, and microvascular system.

\section{CONCLUSION}

The nephroprotective effects of CQ in LPSinduced renal injury can be attributed to the inhibition of the inflammatory response. CQ may play a role in the management renal injury but further studies are required confirm this.

\section{DECLARATIONS}

\section{Acknowledgement}

The authors thank the Department of Anesthesiology, Laiwu Steel Group Hospital, Shandong, China for their generous support of this study.

\section{Conflict of Interest}

No conflict of interest associated with this work.

\section{Contribution of Authors}

The authors declare that this work was done by the authors named in this article and all liabilities pertaining to claims relating to the content of this article will be borne by them.

\section{Open Access}

This is an Open Access article that uses a funding model which does not charge readers or their institutions for access and distributed under the terms of the Creative Commons Attribution License (http://creativecommons.org/licenses/by/ 4.0) and the Budapest Open Access Initiative (http://www.budapestopenaccessinitiative.org/rea d), which permit unrestricted use, distribution, and reproduction in any medium, provided the original work is properly credited.

\section{REFERENCES}

1. Puri VK. Of mice and MODS, TNF-alpha, and sepsis. Crit Care Med 1998; 26: 1160.

2. Oda S, Hirasawa $H$, Sugai T, Shiga $H$, Nakanishi $K$, Kitamura $N$, Sadahiro $T$, Hirano $T$. Comparison of Sepsis-related Organ Failure Assessment (SOFA) score and CIS (cellular injury score) for scoring of severity for patients with multiple organ dysfunction syndrome (MODS). Intensive Care Med 2000; 26: 1786-1793.

3. Bagshaw SM, George C, Bellomo R. ANZICS Database Management Committee. Early acute kidney injury and sepsis: A multicentre evaluation. Crit Care 2008; 12: R47.

4. Schrier RW, Wang W. Acute renal failure and sepsis. $N$ Engl J Med 2004; 351; 159-169.

5. Rajapakse S, Rodrigo C, Rajapakse A, Kirthinanda D, Wijeratne $S$. Renal replacement therapy in sepsisinduced acute renal failure. Saudi J kidney Dis Transpl 2009; 20: 553-559.

6. Nisula $S$, Yang R, Poukkanen M, Vaara ST, Kaukonen KM, Tallgren M, Haapio M, Tenhunen J, Korhonen AM, Pettilä V. FINNAKI Study Group. The FINNAKI Study Group: Predictive value of urine interleukin-18 in the evolution and outcome of acute kidney injury in critically ill adult patients. Br J Anaesth; 2015; 114: 460-8.

7. Yang $Y$, Zhang ZX, Lian D, Haig A, Bhattacharjee $R N$, Jevnikar AM. IL-37 inhibits IL-18 induced tubular epithelial cell expression of pro-inflammatory cytokines and renal ischemia reperfusion injury. Kidney Int; 2015; 87: 396-408.

8. Mahoney E, Maddocks K, Flynn J, Jones J, Cole SL, Zhang $X$, Byrd JC, Johnson AJ. Identification of endoplasmic reticulum stress-inducing agents by antagonizing autophagy: A new potential strategy for identification of anti-cancer therapeutics in $b$-cell malignancies. Leuk Lymphoma 2013; 54: 2685-2692.

9. Blanchard E, Belouzard S, Goueslain L, Wakita T, Dubuisson J, Wychowski C, Rouillé Y. Hepatitis $C$ virus entry depends on clathrin-mediated endocytosis. $J$ Virol 2006; 80: 6964-6972. 
10. Klingenstein R, Melnyk $P$, Leliveld RS, Ryckebusch A, Korth C. Similar Structure Activity Relationships of Quinoline Derivatives for antiprion and antimalarial effects. J Med Chem 2006; 49: 5300-5308.

11. Vodicka P, Lim J, Williams DT, Kegel KB, Chase K, Park $H$, Marchionini D, Wilkinson S, Mead T, Birch H, Yates D, Lyons K, Dominguez C, Beconi M, Yue Z, Aronin N, DiFiglia $M$. Assessment of chloroquine treatment for modulating autophagy flux in brain of WT and HD mice. $J$ Huntington's Dis 2014; 3: 159-174.

12. Costedoat-Chalumeau N, Leroux G, Piette JP, Amoura Z. Why all systemic lupus erythematosus patients should be given hydroxychloroquine treatment? Joint Bone Spine 2010; 77: 4-5.

13. Suarez-Almazor ME, Belseck E, Shea B, Homik J, Wells $G$, Tugwell $P$. Antimalarials for treating rheumatoid arthritis. Cochrane Database Syst Rev 2010; 4: CD000959.

14. European Commission [homepage on the internet]. Directive 2010/63/EU on the protection of animals used for scientific purposes [cited 2013 Jan 16]. Available from: http://ec.europa.eu/environment/chemicals/lab_ani mals/legislation_en.htm.
15. Bonnet $B$, Soullez $D$, Girault $S$, Maes L, Landry V, Davioud-Charvet E, Sergheraert C. Trypanothione Reductase Inhibition/Trypanocidal Activity Relationships in a 1,4-Bis(3-aminopropyl) piperazine Series Bioorg Med Chem 2000; 8: 95-103.

16. Singbartl K, Kellum JA.AKI in the ICU: Definition, epidemiology, risk stratification, and outcomes. Kidney Int 2012; 81: 819-825.

17. Honore PM, Jacobs $R$, JoannesBoyau $O$, De Regt J, Boer W, De Waele E, Collin V, Spapen HD. Septic AKI in ICU patients. Diagnosis, pathophysiology and treatment type, dosing, and timing: A comprehensive review of recent and future developments. Ann Intensive Care 2011; 1: 32.

18. Cunningham PN, Wang Y, Guo R, He G, Quigg RJ. Role of Toll-like receptor 4 in endotoxin-induced acute renal failure. J Immunol 2004; 172: 2629-2635.

19. Hall IE, Yarlagadda SG, Coca SG, Wang Z, Doshi M, Devarajan P, Han WK, Marcus RJ, Parikh CR. IL-18 and urinary NGAL predict dialysis and graft recovery after kidney transplantation. J Am Soc Nephrol 2010; 21: 189-197. 